\title{
Satellite Remote Sensing and Hydrologic Modeling for Flood Inundation Mapping in Lake Victoria Basin: Implications for Hydrologic Prediction in Ungauged Basins
}

\author{
Sadiq I. Khan, Yang Hong, Jiahu Wang, Koray K. Yilmaz, Jonathan J. Gourley, Robert F. Adler, \\ G. Robert Brakenridge, Fritz Policelli, Shahid Habib, and Daniel Irwin
}

\begin{abstract}
Floods are among the most catastrophic natural disasters around the globe impacting human lives and infrastructure. Implementation of a flood prediction system can potentially help mitigate flood-induced hazards. Such a system typically requires implementation and calibration of a hydrologic model using in situ observations (i.e., rain and stream gauges). Recently, satellite remote sensing data have emerged as a viable alternative or supplement to in situ observations due to their availability over vast ungauged regions. The focus of this study is to integrate the best available satellite products within a distributed hydrologic model to characterize the spatial extent of flooding and associated hazards over sparsely gauged or ungauged basins. We present a methodology based entirely on satellite remote sensing data to set up and calibrate a hydrologic model, simulate the spatial extent of flooding, and evaluate the probability of detecting inundated areas. A raster-based distributed hydrologic model, Coupled Routing and Excess STorage (CREST), was implemented for the Nzoia basin, a subbasin of Lake Victoria in Africa. Moderate Resolution Imaging Spectroradiometer Terra-based and Advanced Spaceborne Thermal Emission and Reflection Radiometer-based flood inundation maps were produced over the region and used to benchmark the distributed hydrologic model simulations of inundation areas. The analysis showed the value of integrating satellite data such as precipitation, land cover type, topography, and other products along with space-based flood inundation extents as inputs to the distributed hydrologic model. We conclude that the quantification of flooding spatial extent through optical sensors can help to calibrate and evaluate hydrologic models and, hence, potentially improve hydrologic prediction and flood management strategies in ungauged catchments.
\end{abstract}

Manuscript received November 1, 2009; revised April 21, 2010 and June 14, 2010; accepted June 24, 2010. Date of publication August 30, 2010; date of current version December 27, 2010. This work was supported by the National Aeronautics and Space Administration (NASA) Headquarters under the NASA Earth and Space Science Fellowship Program through Grant NNX08AX63H and under the NASA Applied Sciences SERVIR Africa Project.

S. I. Khan, Y. Hong, and J. Wang are with the School of Civil Engineering and Environmental Sciences, The University of Oklahoma, Norman, OK 73019-1024 USA (e-mail: yanghong@ ou.edu).

K. K. Yilmaz, R. F. Adler, F. Policelli, and S. Habib are with the NASA Goddard Space Flight Center, Greenbelt, MD 20771 USA.

J. J. Gourley is with the NOAA National Severe Storms Laboratory, National Weather Center, Norman, OK 73072 USA.

G. R. Brakenridge is with the Department of Geography and the Department of Earth Sciences, Dartmouth College, Hanover, NH 03755 USA.

D. Irwin is with the NASA Marshall Space Flight Center, Huntsville, AL 35811 USA.

Color versions of one or more of the figures in this paper are available online at http://ieeexplore.ieee.org.

Digital Object Identifier 10.1109/TGRS.2010.2057513
Index Terms-Floods, hydrology, optical sensors, rainfallrunoff modeling, satellite precipitation.

\section{INTRODUCTION}

$\mathbf{F}$ LOODS are among the most recurring and devastating natural hazards, impacting human lives and causing severe economic damage throughout the world. It is understood that flood risks will not subside in the future, and with the onset of climate change, flood intensity and frequency will threaten many regions of the world [1], [2]. The current trend and future scenarios of flood risks demand accurate spatial and temporal information on the potential hazards and risks of floods. Techniques utilizing satellite remote sensing data can provide objective information that help to detect floods and to monitor their spatiotemporal evolution [3]-[5]. For example, orbital sensors, such as National Aeronautics and Space Administration (NASA)'s Moderate Resolution Imaging Spectroradiometer (MODIS), provide reliable data to help detect floods in regions where no other means are available for flood monitoring [6], [7]. Such data, after certain processing, provide information on flooding areal extents with global coverage and frequent (sometimes daily) observations over the region of interest. To date, satellite observations have become practical tools for development of cost-effective methods for hydrologic prediction in poorly gauged or even ungauged basins around the globe, regardless of the political boundaries. It has been demonstrated that orbital remote sensing can be used for river inundation mapping and has the potential to remotely estimate runoff [7], [8].

The application of satellite imagery for flood mapping began with the use of Landsat Thematic Mapper and Multispectral Scanner, the Satellite Pour l'Observation de la Terre [9]-[12], the Advanced Very High Resolution Radiometer [13]-[16], the Advanced Spaceborne Thermal Emission and Reflection Radiometer (ASTER), MODIS, and Landsat-7 sensors [3], [4], [17]-[19]. For a comprehensive review on space-based observation of flood extent and surface water level from various satellite sensors, please refer to [4], [5], [11], and [20]-[24].

Microwave measurements from space can be used for flood monitoring even when cloud cover is present but the spatial resolution is relatively coarse at approximately $10 \mathrm{~km}$, such 

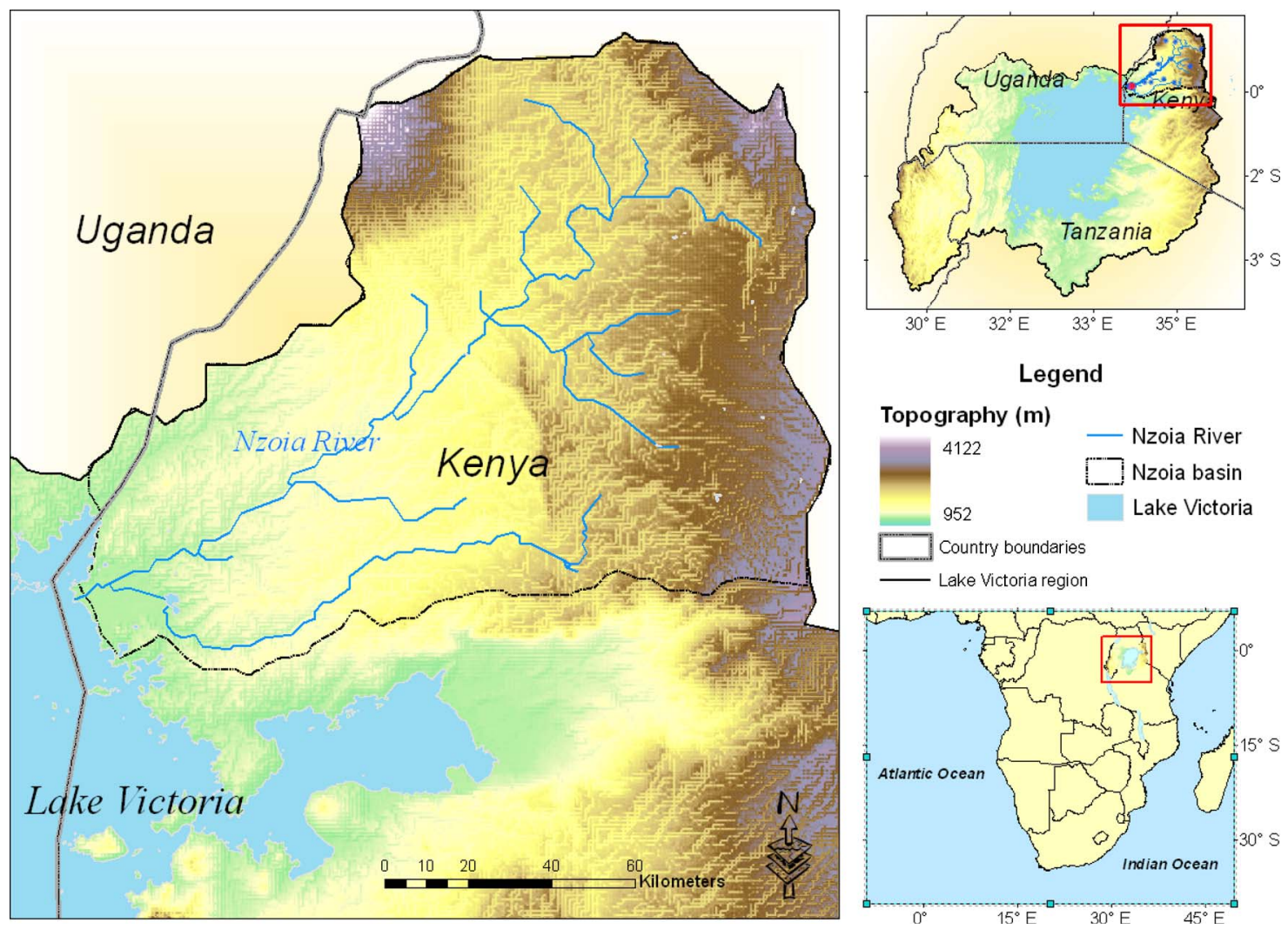

Fig. 1. Map showing the Nzoia river basin in the Lake Victoria region, East Africa.

as with Advance Microwave Scanning Radiometer for the Earth Observing System (AMSR-E) microwave data. Radar imagery onboard satellites has proved invaluable in mapping flood extent [25]-[27]. For example, flood extent maps derived from Synthetic Aperture Radar (SAR) sensors have been used to validate hydraulic models [28], [29]. However, limitations of the SAR include inability to detect flooding in urban areas, inaccurate image calibration that leads to geometric and radiometric distortions, difficulties in data processing, and more prohibitively, low temporal resolution of the current overpasses with a revisit time of 35 days [27]. Other sensors such as the Advanced SAR instrument onboard ENVISAT with a spatial resolution of (150-1000 m) and a revisit time of a few days can be effective for flood detection [24], [27], [28]. Visible and infrared sensors onboard the NASA MODIS Terra satellite can detect floods with relatively high spatial (30 m with ASTER and $250 \mathrm{~m}$ with MODIS) and temporal (daily if clear sky) resolution around the globe. For the past decade, significant efforts have been made in investigating the potential to use flood inundation extent derived from optical sensors as a tool to evaluate the performance of hydrologic models in sparsely gauged or unguaged basins [6], [7].

This study presents a methodology based entirely on satellite remote sensing data (including topography, land cover, precipitation, and flood inundation extent) to calibrate a hydrologic model, simulate the spatial extent of flooding, and evaluate the probability of detecting inundated areas. MODIS- and ASTER-based raster flood inundation maps were derived to benchmark the distributed hydrologic model to simulate the spatial extent of flooding. The objective of this paper is to investigate the utility of flood spatial extent information obtained from orbital sensors to calibrate and evaluate hydrologic models in an effort to potentially improve hydrologic prediction and flood management strategies in ungauged catchments. This paper is organized as follows. Section II describes the study area, data, and the hydrologic model. Section III outlines the methods for space-based flood inundation mapping and for hydrologic model-based flood extent mapping. Section IV provides a comparison between the two methods and validates the model performance using MODIS-/ASTER-derived flood inundation maps, followed by final concluding remarks in Section V.

\section{Study AREA AND DATA}

\section{A. Nzoia Basin}

The rainy season from October to early December brings devastating floods in Uganda, Kenya, Tanzania, and other countries in East Africa almost every year. This region, surrounding Lake Victoria, is heavily populated with around 30 million people (Fig. 1). During December 2006, the United Nations Office for the Coordination of Humanitarian Affairs estimated that 1.8 million people had been affected by the flooding in Kenya, Ethiopia, and Somalia. Repeated flooding affects many lives particularly in the Lake Victoria region. With an area of $68600 \mathrm{~km}^{2}$, Lake Victoria is the second largest freshwater lake in the world [30]. Nzoia, a subbasin of the Lake Victoria basin, was chosen as the study area because of its regional importance as being susceptible to flooding and as a major 
TABLE I

Selected Flood Events, Location, Flooded Areas/River (VERIFIEd With the DFO Flood InVEntory). Numbers in Parentheses ARE THE Julian Days of THE CorResponding Year

\begin{tabular}{|c|c|c|c|}
\hline Events & Images retrieved & Countries & Rivers flooded \\
\hline 1. & 2006/12/04 (338) & $\begin{array}{l}\text { Kenya } \\
\text { Tanzania } \\
\text { Uganda }\end{array}$ & $\begin{array}{l}\text { Kenya: Ewaso Nyiro, Uaso } \\
\text { Nyiro, Tana river and tributaries. } \\
\text { Ramisi. Lak Dera, Lak Bor, } \\
\text { Lagahar. Ndarugu. Sosiani. } \\
\text { Ramisi. Nzoia. Ongoche, Kuja, } \\
\text { Migori, Ongohe. Nyamasaria, } \\
\text { Sabaki. } \\
\text { - } \text { Uganda - River Ssezibwa } \\
\text { - } \text { Tanzania - Wembere, Mwanza }\end{array}$ \\
\hline 2. & $\begin{array}{l}2007 / 08 / 15(227) \\
2007 / 08 / 22(234) \\
2007 / 08 / 24(236)\end{array}$ & $\begin{array}{l}\text { Uganda } \\
\text { Kenya } \\
\text { Tanzania }\end{array}$ & $\begin{array}{l}\text { - } \text { Kenya - Nzoia, Sabwani, } \\
\text { Malakisi, Malaba, Rongai. } \\
\text { - } \text { Uganda - Kirik, Moroto, Aswa, } \\
\text { Ora, Ssezibwa, Dopeth. Muzizi. } \\
\text { Nyangoma } \\
\text { - } \text { Tanzania - Wembere, Mwanza }\end{array}$ \\
\hline 3. & 2008/11/12 (317) & $\begin{array}{l}\text { Kenya } \\
\text { Uganda }\end{array}$ & - Western Kenya, Nzoia River \\
\hline
\end{tabular}

tributary to Lake Victoria. The Nzoia River basin covers approximately $12900 \mathrm{~km}^{2}$ with elevations ranging between 1100 and $3000 \mathrm{~m}$. Annual average rain within the region is $1500 \mathrm{~mm}$. Table I lists the recent flooding events investigated in this study.

\section{B. Satellite Remote Sensing Data for Flood Inundation Mapping}

In this paper, we used MODIS and ASTER for flood inundation mapping. MODIS instruments onboard NASA's Terra and Aqua satellites offer a unique combination of quasi-global daily coverage with acceptable spatial resolution. These capabilities are being utilized for flood monitoring at regional and global scales. Brakenridge et al. [3], [4] demonstrated that MODIS data can be used to distinguish between flooded and nonflooded areas with suitable spatial resolution. This can be very crucial in regions where no other means of flood monitoring are available. The NASA Goddard Space Flight Center, through the Rapid Response System, processes and displays images in near real time-within 2-4 h of retrieval. MODIS Rapid Response data are available from Terra and Aqua in near real time at http://rapidfire.sci.gsfc.nasa.gov/. This system, initially developed for fire hazard detection and monitoring, can be utilized for flood detection across the globe. Several spectral bands at spatial resolutions of approximately 250 and $500 \mathrm{~m}$ are appropriate for accurate discrimination of water from land. Global coverage can be provided on a near-daily basis if sky conditions are cloud free.
Another sensor used in this study is ASTER, an imaging instrument onboard Terra satellite that was launched in December 1999 as part of NASA's Earth Observing System. ASTER is a cooperative effort between NASA, Japan's Ministry of Economy, Trade and Industry, and Japan's Earth Remote Sensing Data Analysis Center. ASTER is an advanced multispectral imager with high spatial, spectral, and radiometric resolution. The ASTER instrument covers a wide spectral range, from visible to thermal infrared with 14 spectral bands. It has a total of 14 bands in visible to near-infrared (VNIR), short-wave infrared (SWIR), and thermal-infrared (TIR) wavelengths. The ground resolutions of the VNIR, SWIR, and TIR images are 15,30 , and $90 \mathrm{~m}$, respectively [31], [32]. Data from this sensor can be acquired on demand from Land Processes Distributed Active Archive Center at the U.S. Geological Survey Earth Resources Observation and Science Data Center, with the standard Hierarchical Data Format (http://LPDAAC.usgs.gov). In this study, the strategies for computing MODIS- and ASTER-based inundation extent are described in Section III.

\section{Data for Hydrologic Model Setup and Implementation}

The key remote sensing data sets enabling the implementation and testing of a distributed hydrologic model in the Nzoia basin include the following.

1) Digital elevation data from the Shuttle Radar Topography Mission (SRTM) [33] (http://www2.jpl.nasa.gov/srtm/) and SRTM-derived hydrologic parameter files of HydroSHEDS [34]. 
2) Rainfall data from the Tropical Rainfall Measuring Mission (TRMM)-based Multisatellite Precipitation Analysis 3B42 Real-Time (TMPA 3B42RT) operating in near real time [35]. The data are available on the TRMM Web site (http://trmm.gsfc.nasa.gov) at $0.25^{\circ} \times 0.25^{\circ}$ spatial and 3-h temporal scales within $50^{\circ}$ north-south latitude band.

3) Soil parameters provided by the Food and Agriculture Organization (2003) (http://www.fao.org/AG/agl/agll/ dsmw.html).

4) MODIS land classification map used for land use/cover, with 17 classes of land cover according to the International Geosphere-Biosphere Program classification [36].

5) Global daily Potential Evapotranspiration data from the Famine Early Warning Systems Network (FEWS NET: http://earlywarning.usgs.gov/Global/index.php).

\section{Methodology}

The methodology consists of three major steps. First, the data from MODIS and ASTER sensors were retrieved and processed to derive flood inundation maps for the selected events (Table I). Second, a grid-based distributed hydrologic model was implemented and further calibrated using the satellite-derived flood inundation maps in the study area. Finally, the performance of hydrologic simulations in the Nzoia basin was evaluated by comparing the simulated flood inundation extents with those derived from MODIS and ASTER imageries. A similar technique described below is used by the Dartmouth Flood Observatory (http://www.dartmouth.edu/ floods/) to generate flood maps.

\section{A. Satellite Remote-Sensing-Based Flood Inundation Mapping}

There are several methods for identifying flooded versus nonflooded areas using optical remote sensing imagery (e.g., [11] and [37]). The first step is to identify spectral classes within the imagery. One of the widely used clustering algorithms for this task is the Iterative Self-Organizing Data Analysis Technique Algorithm (ISODATA), which uses the Euclidean distance in the feature space to assign every pixel to a cluster through a number of iterations [37]. ISODATA begins with either arbitrary cluster means or means of an existing signature set, and each time the clustering repeats, the means of these clusters are shifted. The new cluster means are used for the next iteration. To perform ISODATA, the analyst selects the number of spectral classes, a convergence threshold, and number of iterations for the algorithm, which introduces considerable subjectivity into the classification process [38]. This process of floodwater classification was performed using ENVI software. The method for flood detection and mapping using satellite imagery included the following steps.

1) Terra MODIS near-real-time subsets covering the region of Lake Victoria were retrieved from the NASA Web site http://rapidfire.sci.gsfc.nasa.gov/subsets.

2) Color composite images were downloaded for image processing. The false-color composite of MODIS bands 1, 2, and 7 (red, near-infrared, and SWIR) has a resolution of $250 \mathrm{~m}$. The true-color composite of MODIS bands 1,3 , and 4 was used for visual interpretation.

3) False-color composite images were subset to the region of interest, and ISODATA classification was performed (20 classes and three iterations).

4) All the water classes were combined into one water class.

5) The raster-type images were exported in Geographical Information System (GIS)-compatible format for further processing.

6) The images obtained in step 5) were overlaid on the true-color image to remove the cloud contamination and shadows that were falsely classified as water.

7) The final product overlaid in GIS under a reference water layer (SRTM-based water bodies) was used to identify the flooded areas.

\section{B. Hydrologic Modeling}

A distributed hydrologic model, Coupled Routing and Excess STorage (CREST), developed by Wang et al. [39] was used to generate modeled flood areal extents for comparison with the satellite-based flood inundation maps.

1) Hydrologic Model Description and Implementation: The distributed CREST hydrologic model is a hybrid modeling strategy that was recently developed by The University of Oklahoma (www.hydro.ou.edu) and the NASA SERVIR Project Team (www.servir.net). The main CREST components are briefly described as follows. 1) Three connected layers within the soil profile that control the maximum storage of infiltrating water and thus yield surface runoff generation. The representation of within-cell variability of soil moisture storage capacity (via a spatial probability distribution) and within-cell routing can be employed for simulations at different spatiotemporal scales. 2) Cell-to-cell routing of surface water using a kinematic wave assumption. 3) Coupling between the runoff generation and routing components via feedback mechanisms. This coupling allows for a realistic scalability of the hydrologic variables, such as soil moisture, and is particularly important for simulations at fine spatial resolution.

CREST simulates the spatiotemporal variation of water fluxes and storages on a regular grid with the grid cell resolution being user defined. The scalability of model simulations is accomplished through subgrid scale representation of soil moisture variability (through spatial probability distributions) and physical process representation. CREST can also simulate inundation extent in an effort to obtain spatial and temporal variations of floodwater within the domain. For more information of the CREST model, please refer to [39].

In CREST, parameters related to topography and soil properties are directly estimated from the land surface data shown in the framework in Fig. 2. To apply the CREST model over the Nzoia basin at $1-\mathrm{km}^{2}$ spatial resolution, local drainage direction and accumulation maps were derived from the 30-arc-second resolution SRTM DEM from the HydroSHEDS data set. The precipitation forcing data are TMPA 3B42RT products [35]. The subscript "RT" refers to "real time," which, in reality, refers to a pseudo real time where data become available to the user via the Internet with a 8-16-h latency. Before 


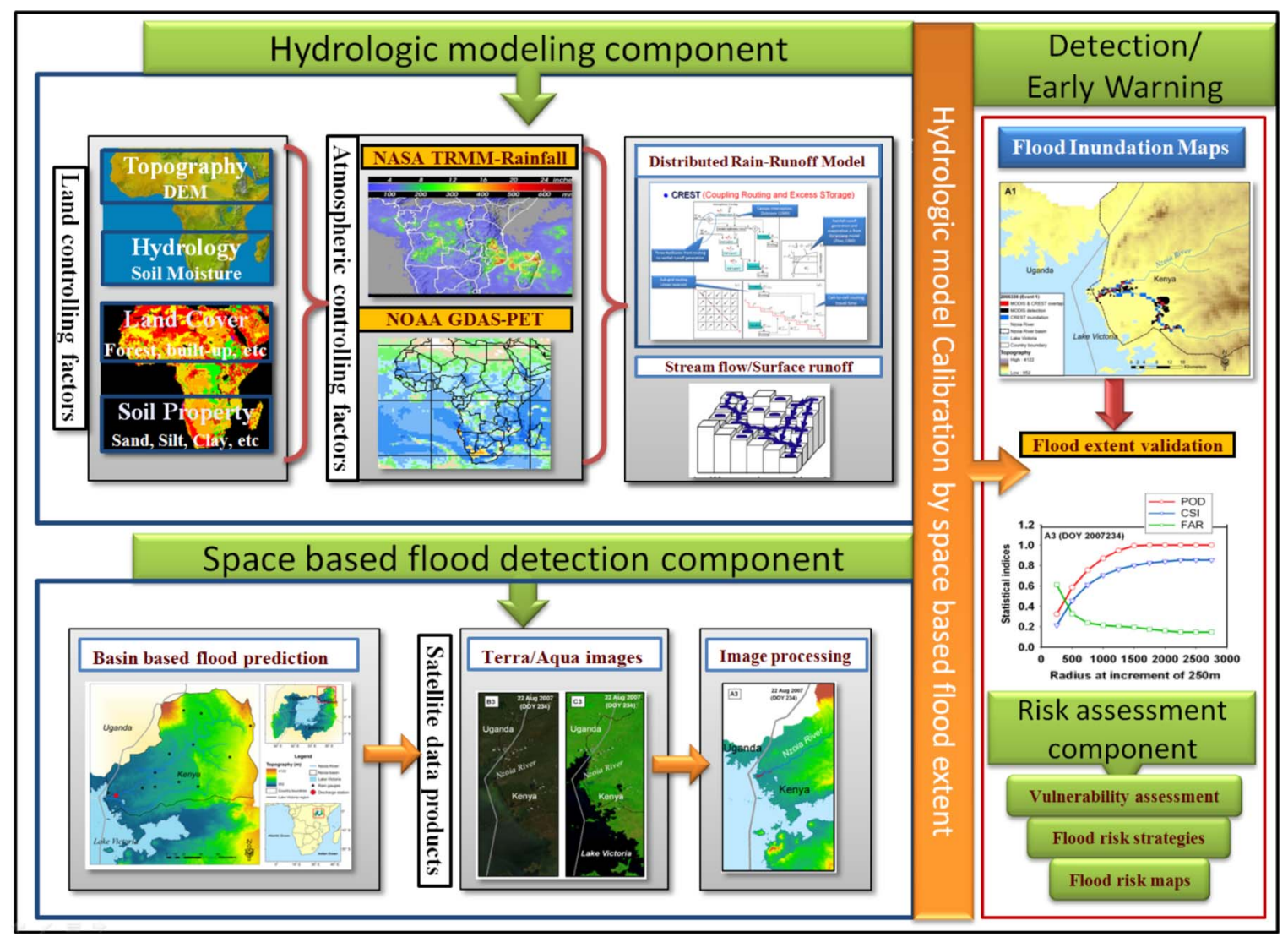

Fig. 2. Schematic of the satellite remote-sensing- and hydrologic-modeling-based flood monitoring system.

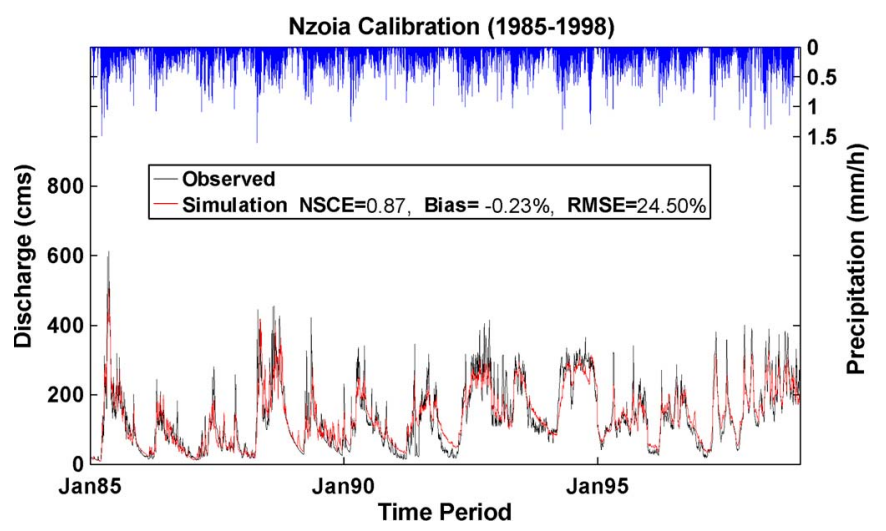

Fig. 3. (In blue on top abscissa) Observed precipitation, (in black) observed runoff, and (in red) simulated runoff for the Nzoia basin during the calibration period (1985-1998).

forcing CREST with the TMPA 3B42RT rainfall, the data were accumulated into daily amounts and linearly resampled onto the 30-arc-second resolution model grid.

2) Model Calibration and Validation: CREST was calibrated using the available daily discharge observations for the period between 1998 and 2004. A one-year period (1998) was used for warming up the model states. The model utilizes a global optimization approach to capture the parameter interactions. An autocalibration technique based on the Adaptive Random Search (ARS) method by Brooks [40] was used to calibrate the CREST model. The ARS method is considered adaptive in the sense that it uses information gathered during previous iterations to guide the parameter search in the current step. The two most commonly used indicators to assess model skill in matching the model-simulated streamflow with observations are the Nash-Sutcliffe Coefficient of Efficiency (NSCE) [41] and the relative bias ratio (Bias). These two criteria are used as objective functions for the automatic calibration. The best skill occurs with $N S C E \approx 1$ and Bias $\approx 0 \%$

$$
\begin{aligned}
N S C E & =1-\frac{\sum\left(Q_{i, o}-Q_{i, c}\right)^{2}}{\sum\left(Q_{i, o}-\bar{Q}_{o}\right)^{2}} \\
\text { Bias } & =\frac{\sum Q_{i, o}-\sum Q_{i, c}}{\sum Q_{i, o}} \times 100 \%
\end{aligned}
$$

where $Q_{i, o}$ is the observed discharge at the $i$ th time step, $Q_{i, c}$ is the simulated discharge at the $i$ th time step, and $\bar{Q}_{o}$ is the average of all the observed discharge values. The ARS search method yielded an optimized parameter combination that had an $N S C E=0.873$ and Bias $=-0.228 \%$ (Fig. 3).

3) Flood Inundation Module: The CREST flood inundation model uses one of the model outputs, the grid-to-grid total free water, to simulate the flood extents. A predefined total free water depth threshold of approximately $70 \mathrm{~mm}$ is employed to determine flood-inundated extents. This value is not fixed but changes with the calibration of satellite-based flood inundation images that are used during the autocalibration process. For more information about CREST model inputs and outputs, please refer to [39]. 
TABLE II

$2 \times 2$ CONTINGENCY TABLE FOR CREST-SIMULATED AND SATELLITE-BASED FloOd EXTENT COMPARISONS

\begin{tabular}{l|c|c|c}
\hline \multicolumn{2}{c|}{} & \multicolumn{2}{c}{ Satellite flood extent } \\
\cline { 3 - 4 } \multicolumn{2}{c|}{} & Yes & No \\
\hline CREST flood extent & Yes & Hit & False alarm \\
\cline { 2 - 4 } & No & Miss & Correct rejection \\
\hline
\end{tabular}

\section{Flood Inundation Evaluation Indexes}

Finally, the CREST-simulated inundation spatial extents were compared with the satellite-derived flood inundation maps. The following several categorical verification statistics, which measure the correspondence between the estimated and observed occurrence of events, were used in this study: probability of detection (POD), false-alarm ratio (FAR), and critical success index (CSI). POD measures the fraction of observed events that were correctly diagnosed and is also called the "hit rate" (Table II). FAR gives the fraction of diagnosed events that were not observed. CSI gives the overall fraction of correctly diagnosed events by CREST. Perfect values for these scores are $P O D=1, F A R=0$, and $C S I=1$

$$
\begin{aligned}
& P O D=\text { Hits } / \text { Hits }+ \text { Misses }) \\
& F A R=\text { False alarms } /(\text { Hits }+ \text { False alarms }) \\
& C S I=\text { Hits } / \text { Hits }+ \text { Misses }+ \text { False alarms }) .
\end{aligned}
$$

CREST was calibrated using MODIS-based flood extent maps for the different events listed in Table I for which gauged streamflow observations are not available. As pointed out earlier, the purpose of this exercise is to investigate the possibility of calibrating the hydrologic model through satellite remote sensing data sets alone. The calibration period includes two cloud-free MODIS images available in 2006 and 2007. The objective function selected to guide the calibration process was the CSI between satellite-based inundation maps and CRESTmodeled flood extents. The calibration terminates when improvements in CSI within the last three iterations are less than 0.001 . The approach can have far-reaching implications for hydrologic prediction in unguaged basins where no other means are available to calibrate a hydrologic model.

\section{RESUlts AND ANALYSis}

In this section, we present the application of the two alternative methods for inundation mapping, namely, CRESTsimulated and satellite-based methods described in Section III, to generate the flood inundation maps for three different flood events in the study area (see Fig. 4 and Table I). The comparison of CREST-simulated flood extent with satellite-based observations will provide an evaluation of the CREST model performance in simulating the spatiotemporal evolution of the flood inundation extent. Unsupervised classification is an automatic and objective process that generates precise flooding maps. However, flood inundation mapping from the binary flood classification using optical sensors can be influenced by cloud and vegetation cover. These lead to underdetection or overdetection due to the influence of riparian vegetation and the natural variability of the water surface, respectively. Comparisons between the CREST- and satellite-based flood inundation extent for the three events listed in Table I are discussed next.

\section{A. Evaluation of Inundation Extent for Event 1}

Fig. 4(B1) and (C1) show true- and false-color composite (bands 7, 2, 1) MODIS scenes, respectively. After the MODIS data were acquired for December 4, the flood extent was derived using the ISODATA classification [Fig. 4(A1)]. The December event was also simulated using the distributed hydrologic model CREST. Intercomparison was made between the satellite-based flood detection and CREST-simulated flood inundation map [Fig. 5(A1)]. The river channel and water bodies are shown as light blue, MODIS detections are in black, and CREST inundations are in blue. The overlapping flooded areas from MODIS and CREST are shown in red. Further examination of flood extents from CREST and MODIS indicates that the spatial patterns of the flood extent are similar, as shown in Fig. 5(A1). To quantify this similarity, a spatial correlation is introduced and analyzed on a pixel-by-pixel basis. If a pixel is classified in the same category (river channel and water bodies and flooded area), on both inundation maps, the pixel is recoded as 1 (a hit); otherwise, it is recorded as a nonflooded area denoted as 0 (a miss).

Fig. 6(A1) shows the statistical comparison between the flood extents derived from MODIS and CREST for the December 2006 event, evaluated as a function of search radius. POD shows an increase from 0.23 to 0.75 to 0.98 for radii of 250 , 1000, and $2000 \mathrm{~m}$, respectively. Fig. 6(A1) also shows that, within a 250-m radius, FAR can be as high as 0.7 . However, by increasing the radius to $1000 \mathrm{~m}, \mathrm{FAR}$ is reduced to 0.18 . The CSI is improved from 0.14 to 0.64 for radii of 250 and $1000 \mathrm{~m}$, respectively. By further increasing the radius to $2000 \mathrm{~m}$, the CSI is improved to 0.92 . Thus, the two maps show a spatial agreement of $92 \%$ at a radius of $2000 \mathrm{~m}$ in Fig. 6(A1).

\section{B. Evaluation of Inundation Extent for Event 2}

A well-documented flood event that occurred during August 2007, with an estimated return period of ten years, was used to validate CREST model performance. Fig. 4(B2)-(B4) and (C2)-(C4) shows the true- and false-color composite (bands 7 , 2, and 1) MODIS scenes, respectively. MODIS-based flood extent maps shown in Fig. 6(A1)-(A4) are derived from the false-color composite scenes for August 15, 22 and 24, 2007, respectively. The statistical comparison between the CREST and MODIS flood inundation extents for these events is shown in Fig. 6(A2)-(A4). Fig. 6(A2) shows that, on August 15, 2007, the POD is increased from 0.37 to 0.93 with an increase in radius from 250 to $1000 \mathrm{~m}$. Similarly, FAR and CSI have shown improvements by increasing the radius for the other days of this event [Fig. 6(A3) and (A4)]. 

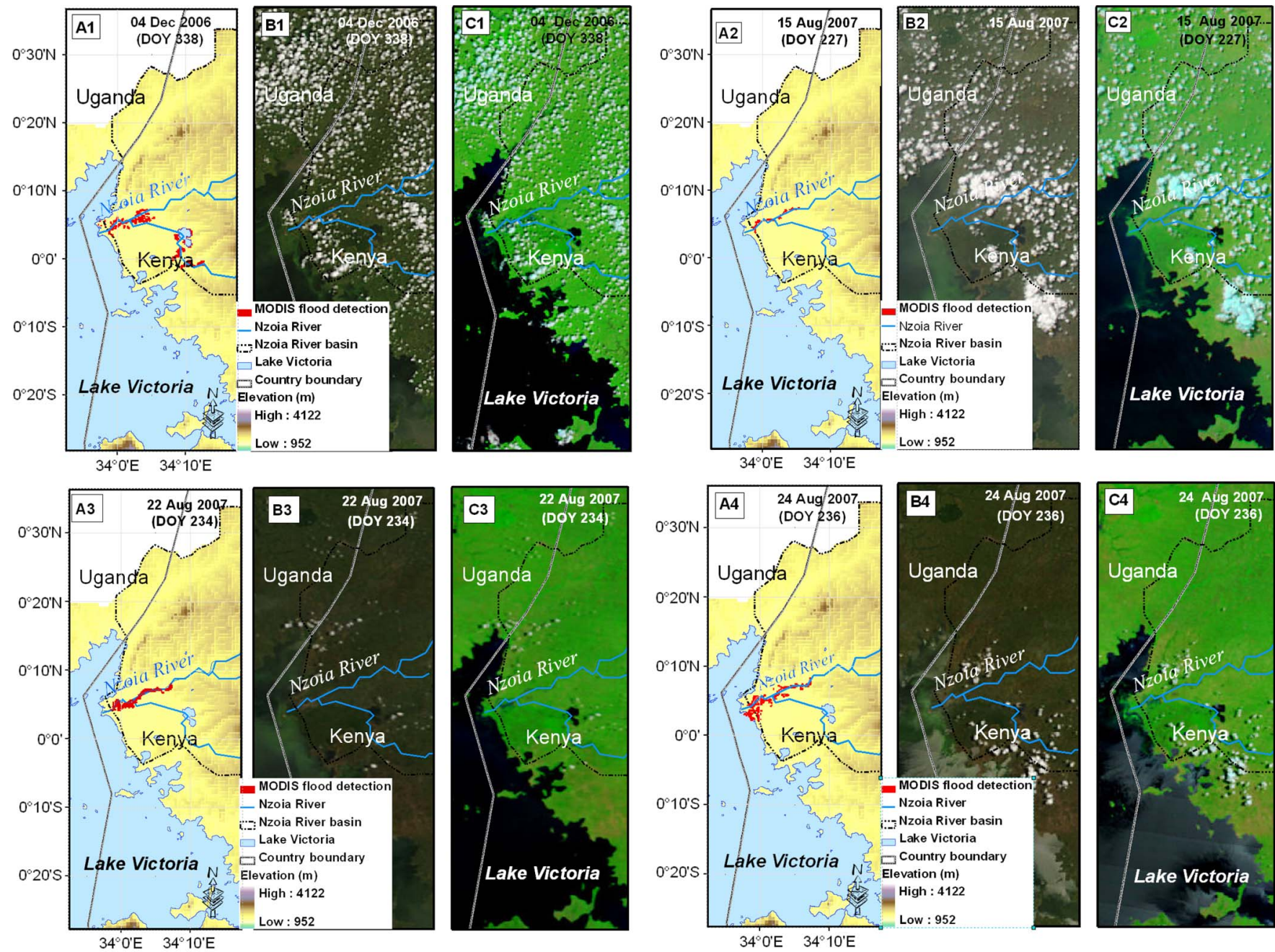

$34^{\circ} \mathrm{O}^{\prime} \mathrm{E} \quad 34^{\circ} 10^{\prime} \mathrm{E}$

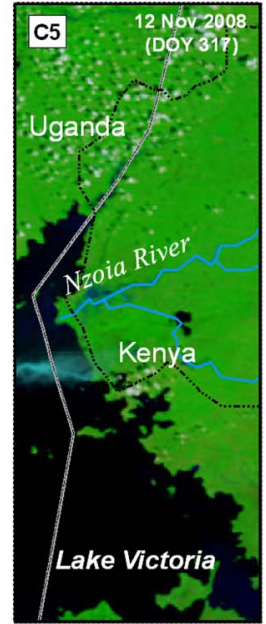

$34^{\circ} 0^{\prime} \mathrm{E} \quad 34^{\circ} 10^{\prime} \mathrm{E}$





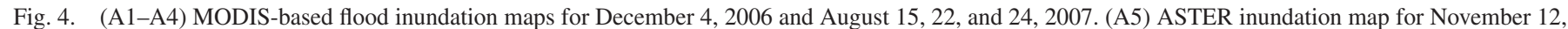
2008. (B1-B5) MODIS true-color composite of bands 1, 3, and 4. (C1-C5) MODIS false-color composite of bands 7, 2 , and 1.

\section{Evaluation of Inundation Extent for Event 3}

For the November 2008 event, the ASTER image with higher spatial resolution is shown in Fig. 4(A5). The POD of CREST shows an increase from 0.46 at a radius of $30 \mathrm{~m}$ to 0.88 at a radius of $600 \mathrm{~m}$. Fig. 6(A5) also shows that, within a 30-m radius, FAR is as high as 0.75 . However, with the increase of the search radius to $600 \mathrm{~m}$, FAR substantially decreases to 0.15 . The CSI is improved from 0.19 at $30 \mathrm{~m}$ to more than 0.76 at a radius of $600 \mathrm{~m}$. 

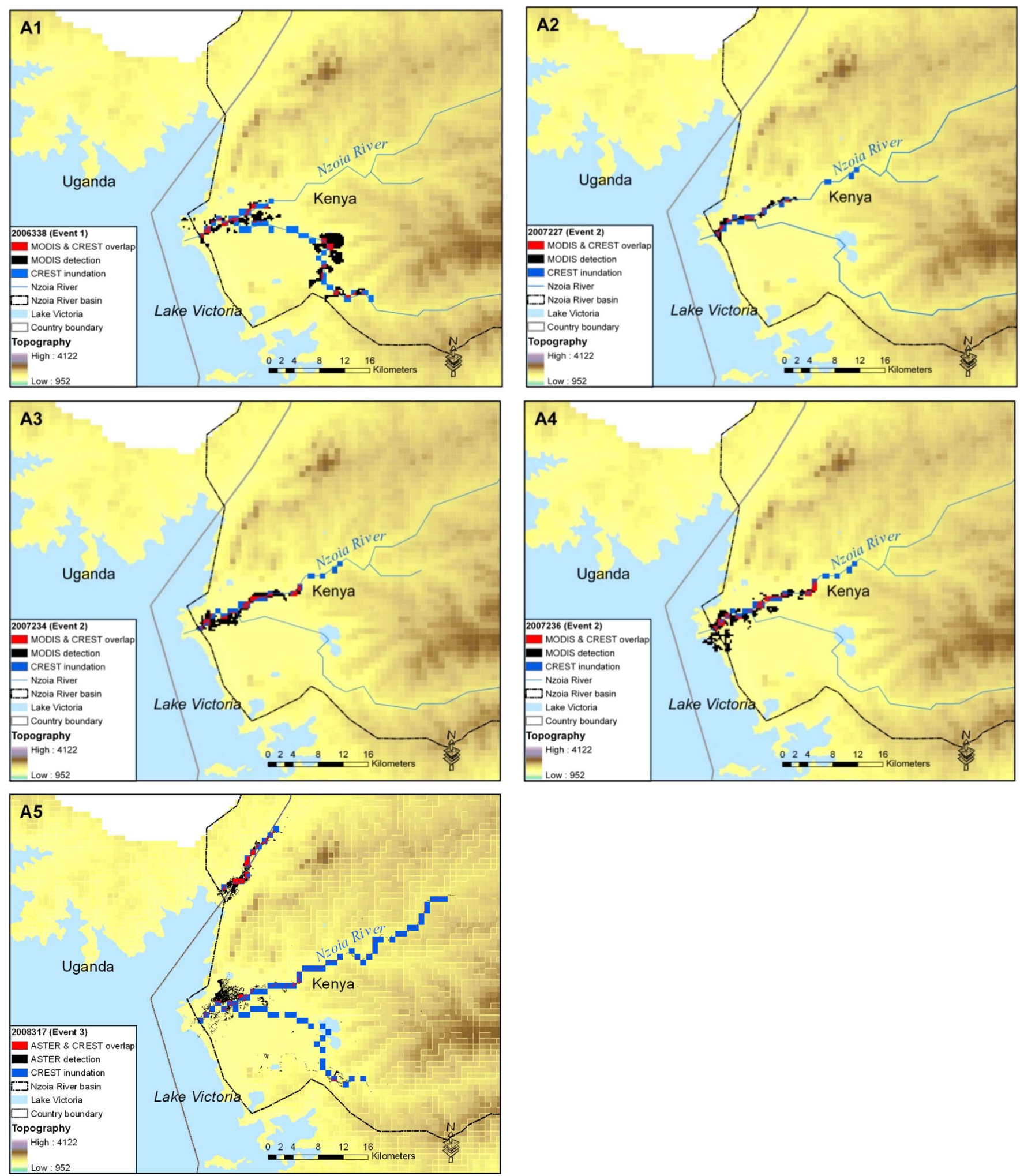

Fig. 5. Comparison of satellite-based and CREST-simulated flood inundation extents. First legend entry is the year and the Julian day of the flood event, followed by the event identification number (refer to Table I).

\section{CONCLUSION AND Future WORK}

We have studied the feasibility of setting up and calibrating a distributed hydrologic model using satellite-based forcing, parameters, and observations of flood inundation extents. This approach is in contrast to the conventional method of flood- modeling techniques, which are often not available in ungauged basins or data sparse regions. The proposed approach implements a distributed hydrologic model with remote sensing data and further calibrates the model parameters through satellitebased flood inundation maps. Utilizing satellite-based data sets 




$$
\begin{aligned}
& \multimap \text { POD } \\
& \square-\text { CSI } \\
& \square \text { FAR }
\end{aligned}
$$
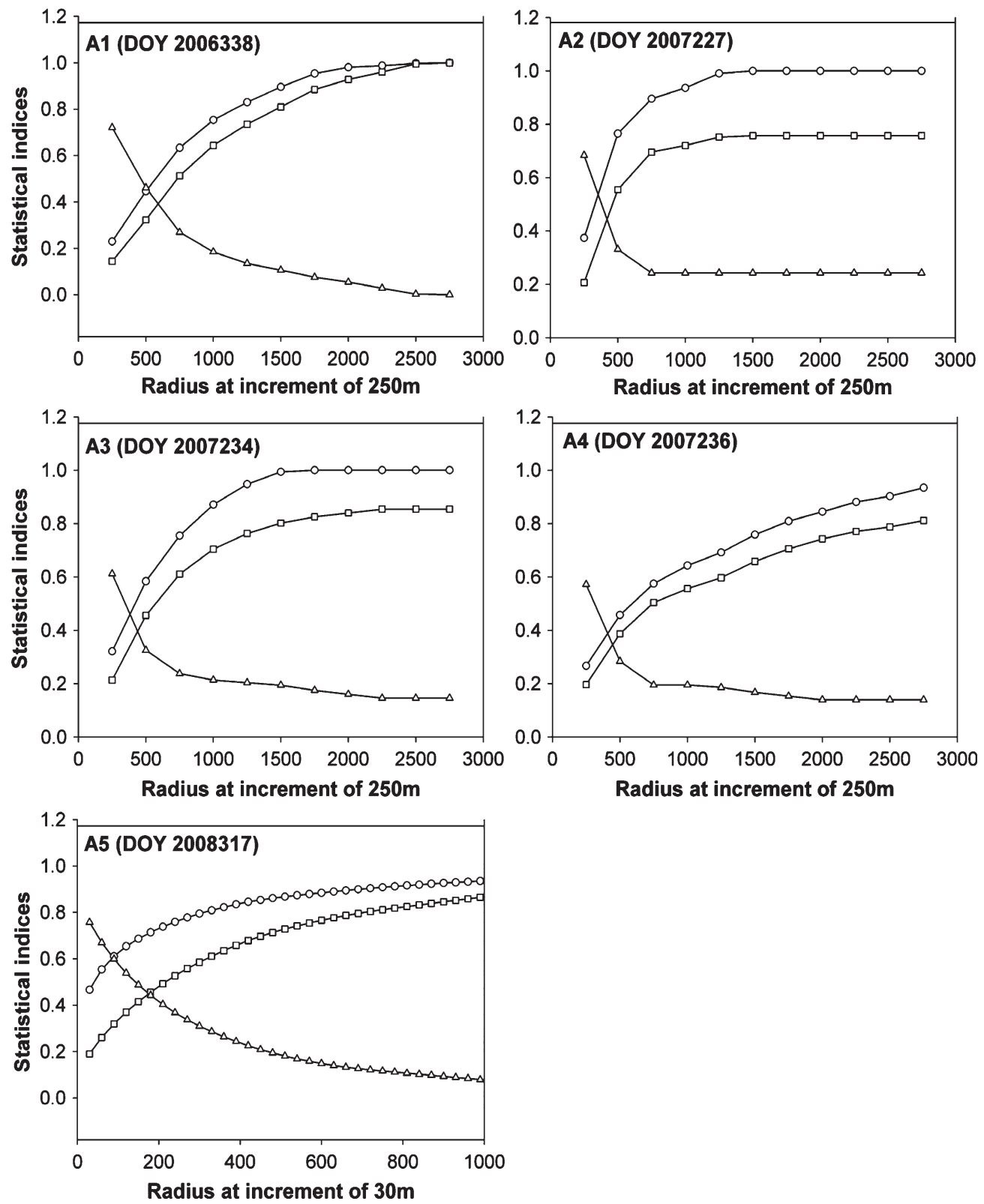

Fig. 6. Evaluation of hydrologic model-based spatial flood extents using inundated areas derived from (A1-A4) MODIS and (A5) ASTER. Evaluation is performed as a function of search radius.

that are freely available in the public domain and integrating them with distributed hydrologic models has the potential to improve simulation and prediction of the spatial extent of floods, even in ungauged basins. The broader impact of such a demonstrated technique is to provide a cost-effective tool to progressively build capacity for flood disaster prediction and risk reduction in poorly or ungauged basins located in many lesser developed or developing countries in Africa or South Asia. Operationally implementing this strategy in those areas will provide flood managers and international aid organizations a realistic decision-support tool in order to better assess imminent flood impacts. This paper has demonstrated the applicability of distributed hydrologic model calibration using satellite-derived flood inundation maps from MODIS and ASTER images in gauged basins.

The recent release of the ASTER Global Digital Elevation Model with a resolution of $30 \mathrm{~m}$ and satellite-based precipitation products at high temporal resolution (e.g., TRMM at 3-h resolution) can be used to implement, calibrate, and force distributed hydrologic models for flood prediction purposes. Thus, further research on how to utilize spatially distributed observations, such as high-resolution imagery and other microwave sensors, should be carried out in various geographical locations for the calibration and evaluation of distributed 
hydrologic models. The case studies on the Nzoia basin that we have presented illustrate that, for regions with scarce groundbased observations, remote sensing data can be used to implement hydrologic models with sufficient accuracy in predicting spatial flood extents. It is noted that further improvements in flood monitoring will be made possible with the integration of satellite remote sensing products with ground-based observations and details of catchment properties.

\section{ACKNOWLEDGMENT}

The authors would like to thank the three anonymous reviewers for their critical comments and constructive suggestions.

\section{REFERENCES}

[1] S. N. Jonkman, "Global perspectives on loss of human life caused by floods," Nat. Hazards, vol. 34, no. 2, pp. 151-175, Feb. 2005.

[2] J. McCarthy, Climate Change 2001: Impacts, Adaptation, and Vulnerability: Contribution of Working Group II to the Third Assessment Report of the Intergovernmental Panel on Climate Change. Cambridge, U.K.: Cambridge Univ. Press, 2001.

[3] G. Brakenridge, E. Anderson, S. Nghiem, S. Caquard, and T. B. Shabaneh, "Flood warnings, flood disaster assessments, and flood hazard reduction: The roles of orbital remote sensing," in Proc. 30th Int. RSE, Honolulu, HI, Nov. 10-14, 2003.

[4] L. C. Smith, "Satellite remote sensing of river inundation area, stage, and discharge: A review," Hydrol. Process., vol. 11, no. 10, pp. 1427-1439, 1997.

[5] G. R. Brakenridge, S. V. Nghiem, E. Anderson, and R. Mic, "Orbital microwave measurement of river discharge and ice status," Water Resour. Res., vol. 43, no. 4, p. W04 405, 2007.

[6] R. Brakenridge, "MODIS-based flood detection, mapping and measurement: The potential for operational hydrological applications," in Transboundary Floods: Reducing Risks Through Flood Management. New York: Springer-Verlag, 2006, pp. 1-12.

[7] C. M. Birkett, L. A. K. Mertes, T. Dunne, M. H. Costa, and M. J. Jasinski, "Surface water dynamics in the Amazon Basin: Application of satellite radar altimetry," J. Geophys. Res._Atmos., vol. 107, no. D20, p. 8059, 2002.

[8] F. Blasco, M. F. Bellan, and M. U. Chaudhury, "Estimating the extent of floods in Bangladesh using SPOT data," Remote Sens. Environ., vol. 39, no. 3, pp. 167-178, Mar. 1992.

[9] M. France and P. Hedges, "A hydrological comparison of Landsat TM, Landsat MSS, and black and white aerial photography," in Proc. 7th Int. Symp. ISPRS, Enschede, The Netherlands, Aug. 1986, pp. 717-720.

[10] J. R. Jensen, M. E. Hodgson, E. Christensen, H. E. Mackey, L. R. Tinney, and R. R. Sharitz, "Remote-sensing inland wetlands-A multispectral approach," Photogramm. Eng. Remote Sens., vol. 52, no. 1, pp. 87-100, 1986.

[11] J. P. Watson, "A visual interpretation of a LANDSAT mosaic of the Okavango-delta and surrounding area," Remote Sens. Environ., vol. 35, no. 1, pp. 1-9, Jan. 1991.

[12] I. J. Barton and J. M. Bathols, "Monitoring floods with AVHRR," Remote Sens. Environ., vol. 30, no. 1, pp. 89-94, Oct. 1989.

[13] S. J. Gale and S. Bainbridge, "The floods in eastern Australia," Nature, vol. 345 , no. 6278 , p. $767,1990$.

[14] H. Rasid and M. Pramanik, "Areal extent of the 1988 flood in Bangladesh: How much did the satellite imagery show?" Nat. Hazards, vol. 8, no. 2, pp. 189-200, Sep. 1993.

[15] I. Sandholt, L. Nyborg, B. Fog, M. Lô, O. Boucum, and K. Rasmussen, "Remote sensing techniques for flood monitoring in the Senegal River Valley," Geogr. Tidsskr., vol. 103, no. 1, pp. 71-81, 2003.

[16] G. Brakenridge and E. Anderson, "Satellite gaging reaches: A strategy for MODIS-based river monitoring," in Proc. 9th Int. Symp. Remote Sens., Crete, Greece, 2003, vol. 4886, pp. 479-485.

[17] G. Stancalie, A. Diamandi, C. Corbus, and S. Catana, "Application of EO data in flood fore-casting for the Crisuri Basin, Romania," in Flood Risk Management: Hazards, Vulnerability and Mitigation Measures. New York: Springer-Verlag, 2004, p. 101.

[18] Y. Wang, "Using Landsat 7 TM data acquired days after a flood event to delineate the maximum flood extent on a coastal floodplain," Int. J. Remote Sens., vol. 25, no. 5, pp. 959-974, Mar. 2004.
[19] Y. Wang, J. D. Colby, and K. A. Mulcahy, "An efficient method for mapping flood extent in a coastal floodplain using Landsat TM and DEM data," Int. J. Remote Sens., vol. 23, no. 18, pp. 3681-3696, Sep. 2002.

[20] C. Puech and D. Raclot, "Using geographical information systems and aerial photographs to determine water levels during floods," Hydrol. Process., vol. 16, no. 8, pp. 1593-1602, Jun. 2002.

[21] D. Alsdorf, D. Lettenmaier, and C. Vörösmarty, "The need for global, satellite-based observations of terrestrial surface waters," EOS Trans. $A G U$, vol. 84, no. 29, pp. 275-276, 2003.

[22] D. Alsdorf, E. Rodríguez, and D. Lettenmaier, "Measuring surface water from space," Rev. Geophys., vol. 45, no. 2, p. RG2 002, 2007.

[23] W. Marcus and M. Fonstad, "Optical remote mapping of rivers at submeter resolutions and watershed extents," Earth Surf. Process. Landforms, vol. 33, no. 1, pp. 4-24, Jan. 2008.

[24] G. Schumann, P. Bates, M. Horritt, P. Matgen, and F. Pappenberger, "Progress in integration of remote sensing-derived flood extent and stage data and hydraulic models," Rev. Geophys., vol. 47, no. 4, p. RG4 001, 2009.

[25] M. S. Horritt, "Calibration of a two-dimensional finite element flood flow model using satellite radar imagery," Water Resour. Res., vol. 36, no. 11, pp. 3279-3291, 2000.

[26] M. S. Horritt and P. D. Bates, "Evaluation of 1D and 2D numerical models for predicting river flood inundation," J. Hydrol., vol. 268, no. 1-4, pp. 87-99, Nov. 2002.

[27] G. Schumann, R. Hostache, C. Puech, L. Hoffmann, P. Matgen, F. Pappenberger, and L. Pfister, "High-resolution 3-D flood information from radar imagery for flood hazard management," IEEE Trans. Geosci. Remote Sens., vol. 45, no. 6, pp. 1715-1725, Jun. 2007.

[28] G. Di Baldassarre, G. Schumann, and P. D. Bates, "A technique for the calibration of hydraulic models using uncertain satellite observations of flood extent," J. Hydrol., vol. 367, no. 3/4, pp. 276-282, Apr. 2009.

[29] M. S. Horritt, G. Di Baldassarre, P. D. Bates, and A. Brath, "Comparing the performance of a 2-D finite element and a 2-D finite volume model of floodplain inundation using airborne SAR imagery," Hydrol. Process., vol. 21, no. 20, pp. 2745-2759, Sep. 2007.

[30] S. Swenson and J. Wahr, "Monitoring the water balance of Lake Victoria, East Africa, from space," J. Hydrol., vol. 370, no. 1-4, pp. 163-176, May 2009.

[31] H. Fujisada, F. Sakuma, A. Ono, and M. Kudoh, "Design and preflight performance of ASTER instrument protoflight model," IEEE Trans. Geosci. Remote Sens., vol. 36, no. 4, pp. 1152-1160, Jul. 1998.

[32] Y. Yamaguchi, A. B. Kahle, H. Tsu, T. Kawakami, and M. Pniel, "Overview of Advanced Spaceborne Thermal Emission and Reflection Radiometer (ASTER)," IEEE Trans. Geosci. Remote Sens., vol. 36, no. 4, pp. 1062-1071, Jul. 1998.

[33] B. Rabus, M. Eineder, A. Roth, and R. Bamler, "The Shuttle Radar Topography Mission-A new class of digital elevation models acquired by spaceborne radar," ISPRS J. Photogramm., vol. 57, no. 4, pp. 241-262, Feb. 2003.

[34] B. Lehner, K. Verdin, and A. Jarvis, "New global hydrography derived from spaceborne elevation data," EOS, vol. 89, no. 10, pp. 93-94, 2008.

[35] G. J. Huffman, R. F. Adler, D. T. Bolvin, E. J. Nelkin, D. B. Wolff, G. Gu, Y. Hong, K. P. Bowman, and E. F. Stocker, "The TRMM multisatellite precipitation analysis (TMPA): Quasi-global, multiyear, combined-sensor precipitation estimates at fine scales," J. Hydrometeorol., vol. 8, no. 1, pp. $38-55$, Feb. 2007

[36] M. A. Friedl, D. K. McIver, J. C. F. Hodges, X. Y. Zhang, D. Muchoney, A. H. Strahler, C. E. Woodcock, S. Gopal, A. Schneider, A. Cooper, A. Baccini, F. Gao, and C. Schaaf, "Global land cover mapping from MODIS: Algorithms and early results," Remote Sens. Environ., vol. 83, no. 1/2, pp. 287-302, Nov. 2002.

[37] J. Jensen, Introductory Digital Image Processing: A Remote Sensing Perspective. Upper Saddle River, NJ: Prentice-Hall PTR, 2005.

[38] R. L. Lang, G. F. Shao, B. C. Pijanowski, and R. L. Farnsworth, "Optimizing unsupervised classifications of remotely sensed imagery with a data-assisted labeling approach," Comput. Geosci., vol. 34, no. 12, pp. 1877-1885, Dec. 2008.

[39] J. Wang, Y. Hong, L. Li, J. J. Gourley, K. Yilmaz, S. Khan, F. S. Policelli, R. F. Adler, S. Habib, D. Irwn, T. Korme, and L. Okello, "The Coupled Routing and Excess STorage (CREST) distributed hydrological model," Hydrol. Sci. J., 2010, to be published.

[40] S. H. Brooks, "A discussion of random methods for seeking maxima," Oper. Res., vol. 6, no. 2, pp. 244-251, Mar./Apr. 1958.

[41] J. Nash and J. Sutcliffe, "River flow forecasting through conceptual models. Part I-A discussion of principles," J. Hydrol., vol. 10, no. 3, pp. 282-290, Apr. 1970. 


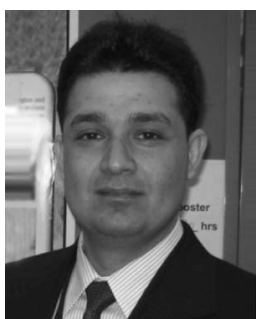

Sadiq I. Khan is currently working toward the Ph.D. degree in the College of Atmospheric and Geographic Sciences, The University of Oklahoma, Norman.

He is currently also a Graduate Research Assistant with the School of Civil Engineering and Environmental Science, The University of Oklahoma. His fields of interest include flood hydrology and remote sensing in hydrology, particularly optical and microwave remote sensing for flood hydrology and management.

Mr. Khan is a member of the American Geophysical Union, Association of American Geographers, and American Society for Photogrammetry and Remote Sensing. He is the recipient of the NASA Earth and Space Science Fellowship and was selected for an outstanding student paper award for the research work he presented at the American Geophysical Union Fall 2009 Meeting in San Francisco, CA.

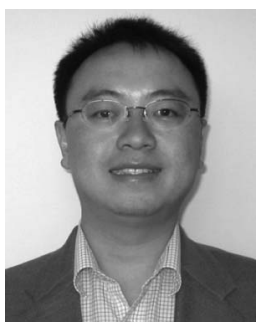

Yang Hong received the B.S. and M.S. degrees in geosciences and environmental sciences from Peking University, Beijing, China, and the Ph.D. degree, major in hydrology and water resources and minor in remote sensing and spatial analysis, from The University of Arizona, Tucson.

Following a postdoctoral appointment at the Center for Hydrometeorology and Remote Sensing, University of California, Irvine, he joined the NASA Goddard Space Flight Center, Greenbelt, MD, in 2005. He is currently an Associate Professor with the School of Civil Engineering and Environmental Sciences, The University of Oklahoma, Norman, where he is also directing the Remote Sensing Water Hydrology research group. He also serves as the Associate Director of the Center for Natural Hazards and Disaster Research and an affiliated Faculty Member with the Atmospheric Radar Research Center, Center for Spatial Analysis, and Water Technology for Emerging Regions Center. He has served in the editorial boards of the International Journal of Remote Sensing, the Natural Hazards journal, and the Landslides journal. His primary research interests are in remote-sensing retrieval and validation, hydrology and water resources, natural hazard prediction, land surface modeling, and data assimilation systems for water resource planning under changing climate.

Dr. Hong is currently the American Geophysical Union Precipitation Committee Chair

Jiahu Wang, photograph and biography not available at the time of publication.

Koray K. Yilmaz, photograph and biography not available at the time of publication.



Jonathan J. Gourley received the B.S. and M.S. degrees in meteorology with a minor in hydrology and the Ph.D. degree in civil engineering and environmental science from the University of Oklahoma, Norman.

$\mathrm{He}$ is currently a Research Hydrometeorologist with NOAA's National Severe Storms Laboratory, is an affiliate Associate Professor with the School of Meteorology, University of Oklahoma, and Director of the National Weather Center's seminar series. His research focuses on rainfall observations from remote sensing platforms with an emphasis on ground-based radars and implementing these high-resolution observations into hydrologic models. $\mathrm{He}$ completed a postdoctoral study with researchers in Paris, France to demonstrate the capabilities of dual-polarimetric radar in improving data quality, microphysical retrievals, and precipitation estimation. MeteoFrance has subsequently upgraded several of their operational radars with polarimetric technology.

Dr. Gourley received the Department of Commerce Silver Medal Award in 1999 "For developing an important prototype Warning Decision Support System for weather forecasters and making significant enhancements to the NEXRAD system, resulting in more timely and reliable warnings." He also received an Honorable Mention in 2004 from the Universities Council on Water Resources Dissertation Awards Committee.

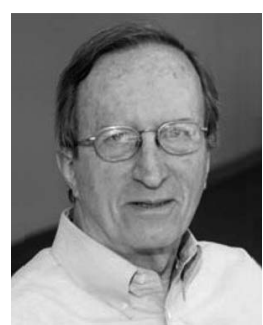

Robert F. Adler received the B.S. and M.S. degrees from The Pennsylvania State University, University Park, in 1965 and 1967, respectively, and the Ph.D. degree from Colorado State University, Fort Collins, in 1974 .

His research focuses on the analysis of precipitation observations from space on global and regional scales using Tropical Rainfall Measuring Mission (TRMM) data along with data from other satellites. He studies precipitation variations in relation to phenomena such as El Niño/Southern Oscillation, volcanoes, and tropical cyclones, as well as longer interdecadal changes or variations. He also leads the group that produces the global monthly and daily precipitation analyses for the World Climate Research Program Global Precipitation Climatology Project. He has published 80 papers in scientific journals on the aforementioned topics. He is currently the TRMM Project Scientist of the NASA Goddard Space Flight Center, Greenbelt, MD.

Dr. Adler is a Fellow of the American Meteorological Society. He was the recipient of the Goddard Space Flight Center Exceptional Performance Award in 1980, the NASA Exceptional Scientific Achievement Medal in 1989, the NASA Outstanding Leadership Medal in 2002, and the Goddard Laboratory for Atmospheres Scientific Leadership Award in 2002.

G. Robert Brakenridge, photograph and biography not available at the time of publication.

Fritz Policelli, photograph and biography not available at the time of publication.

Shahid Habib, photograph and biography not available at the time of publication.

Daniel Irwin, photograph and biography not available at the time of publication. 